\title{
Aislamiento y caracterización de cepas nativas de Lactobacillus spp. para su uso como probióticos en la industria láctea
}

\author{
Vázquez, S. ${ }^{*(1,2)}$, Lopretti, M. ${ }^{(1,2)}$, Rey, F. ${ }^{(1)}$, Zunino, . $^{(3)}$ \\ Contacto: sylvia.vazquez.zeballos@gmail.com \\ (1)Departamento de Biotecnología y Bioprocesos - Laboratorio Tecnológico del Uruguay (LATU) \\ ${ }^{(2)}$ Laboratorio de Bioquímica y Biotecnología - Centro de Investigaciones Nucleares - Facultad de Ciencias

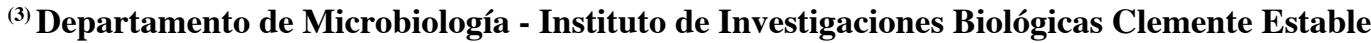

\begin{abstract}
Resumen:
La utilización de fermentos en la elaboración de productos lácteos es una práctica diaria a nivel industrial. En nuestro país los mismos son comprados a multinacionales extranjeras que se dedican a producir y comercializar fermentos; muchos de los cuales incorporan bacterias probióticas. Los probióticos pueden definirse como microorganismos que luego de ser consumidos en cantidades adecuadas, confieren algún efecto benéfico en el huésped.

En el presente trabajo se realizó el aislamiento de una cepa de Lactobacillus de origen humano. Se identificó por tinción gram, prueba catalasa, crecimiento en anaerobiosis y aerobiosis y un test API $50 \mathrm{CH}$.

Con el objetivo de probar propiedades probióticas de la cepa se llevaron a cabo estudios de resistencia al pH, tolerancia a sales biliares y se realizó un Modelo Gástrico in vitro.

Los resultados permiten afirmar que estamos en presencia de una cepa nativa de Lactobacillus acidophilus caracterizada fenotípicamente con un $97 \%$ de confianza. Presentaría la habilidad de sobrevivir al pasaje a través del tubo digestivo ya que resistió la exposición a un pH similar al estomacal, pudo crecer en un medio con sales biliares y sobrevivió a la acción conjunta de la pepsina y una simulación de jugo gástrico; características que permiten clasificarla como posible cepa probiótica.
\end{abstract}

\begin{abstract}
:
The use of starters to elaborate dairy products is a current practice in the industry. In our Country we import these starters from foreign companies dedicated to make and sale it, and most of them include probiotic bacterias.

Probiotics can be defined as microorganisms that after be consumed in adequate amount, can give some advantageous effect to the host.

In this study a strain of Lactobacillus was isolated from a human. The identification was done through gram stain, catalase test, aerobic and anaerobic growth, and an API $50 \mathrm{CH}$ test.

In order to prove the probiotic properties of the strain, studies of pH resistance, bile salts tolerance and an in vitro gastric model were conducted.

The results indicate that the isolate correspond to a native strain of Lactobacillus acidophilus phenotipically characterized with a $97 \%$ of confidence.

What is more, because it capability to resist the exposure to a pH similar than the stomach, to growth in a medium with bile salts and to survive to the simultaneous action of pepsine and gastric juice, it would be able to survive the passage through the digestive tube. These characteristics allow us to classify it as a probiotic strain.
\end{abstract}

\section{Introducción}

L a utilización de fermentos en la elaboración de productos lácteos es una práctica que se realiza hace cientos de años en todo el mundo. En nuestro país las compañías nacionales y multinacionales productoras de lácteos compran los starters a empresas extranjeras que se dedican a desarrollar y producir fermentos. Los fermentos lácticos o cultivos iniciadores se pueden definir como cultivos de microorganismos utilizados para producir cambios bioquímicos durante la elaboración y maduración de los diversos productos lácteos (Borbonet, 2001). Están constituídos por bacterias que fermentan la lactosa produciendo ácido láctico junto a bacterias que fermentan el ácido cítrico y los citratos para obtener diversos aromas (Madrid, 1990).

El yogur es el producto ácido y coagulado elaborado con el cultivo mixto de Lactobacillus bulgaricus y Streptococcus thermophillus a partir de leche pasteurizada de vaca, oveja, búfala y cabra, de forma que los microorganismos estén presentes y viables en el producto en un mínimo de 10 millones de bacterias por gramo (Tamime et al., 1991). Frecuentemente se fabrican yogures con fines dietéticos o terapeúticos que tiene la particularidad de incorporar bacterias probióticas. Los probióticos han sido definidos como microorganismos vivos que cuando son administrados en cantidades adecuadas confieren un efecto benéfico en la salud del huésped (FAO/WHO, 2001). Se han establecido requisitos que deben cumplir las bacterias para poder ser utilizadas como probióticos e incluyen: i) adhesión a células epiteliales, ii) reducción o exclusión de la adherencia de patógenos, iii) persistencia y multiplicación en el trato gastrointestinal y/o vaginal, iv) producción de ácidos, peróxidos, bacteriocinas y/o biosurfactantes v) ser seguros, no invasivos, no carcinogénicos, no patogénicos vi) coagregación y formación de flora normal balanceada y vii) resistencia al pH estomacal y sales biliares (Reid, 1999).

Los probióticos han sido utilizados terapéuticamente con muchos fines principalmente como alternativa al consumo de antibióticos. Se los ha utilizado por ejemplo para modular la inmunidad en casos de alergias producidas por antígenos alimentarios, disminuir el colesterol, prevenir el cáncer, mejorar la intolerancia a la lactosa de pequeños lactantes, en diarrea y constipación, en infecciones urinarias, en infecciones gastrointestinales, en la candidiasis vaginal, (Reid, 1999).

El objetivo del presente trabajo fue aislar una cepa de Lactobacillus spp. de origen humano a los efectos que sea apta para el consumo, realizar su identificación fenotípica y probar propiedades probióticas básica como son resistencia a sales biliares y $\mathrm{pH}$. 


\section{Materiales y métodos}

\section{Aislamientos e identificación}

A partir de materia fecal de un bebe lactante de 4 meses alimentado a pecho exclusivo desde el nacimiento, se realizaron cultivos en caldo MRS por 24-48 hs, en una jarra de anaerobiosis (AnaeroJar, OXOID), sin agitación a una temperatura de entre 37$40^{\circ} \mathrm{C}$. A partir del mismo se realizaron aislamientos y sucesivos reaislamientos en MRS agar en las mismas condiciones. Fueron sometidos a la prueba de producción de catalasa, tinción de Gram, crecimiento en aerobiosis y anaerobiosis y un test para Lactobacilus API $50 \mathrm{CH}$, analizado por el API LAB Plus software Versión 4.0 (bioMérieux, Marcy l'Etoile, France).

A los efectos de verificar la pureza del cultivo se realizaron cultivos en un medio no selectivo PCA (Plate Count Agar), a 37 y $40^{\circ} \mathrm{C}$ en condiciones tanto de aerobiosis como anaerobiosis. Se realizó tinción de Gram, prueba de producción de catalasa y observación morfológica del tipo de colonias que se desarrollaron.

\section{Tolerancia a sales biliares}

La sensibilidad a las sales biliares se analizó sobre placas de MRS conteniendo $0.5 \%$ y $0.9 \%$ de sales biliares deshidratadas (Difco) y sobre agar sin sales biliares como control (Klaenhammer et al., 1995). Las placas se incubaron por 24 y 48 hs y posteriormente se realizaron los recuentos.

En resumen, a partir de una placa de cultivo fresco se transfirieron colonias a un tubo que contenía solución salina fisiológica $(\mathrm{NaCl} 0,9$ $\%)$ y se ajustó la concentración celular en 1.5 x 108 u.f.c/ml por medida de absorbancia a $560 \mathrm{~nm}$. Se realizaron diluciones seriadas en solución fisiológica estéril para poder realizar recuento en superficie. Se sembraron $0.1 \mathrm{ml}$ de la dilución correspondiente en placas conteniendo MRS y MRS con $0.5 \%$ y $0.9 \%$ v/v de sales biliares. Las placas se incubaron a $37^{\circ} \mathrm{C}$ en jarra de anaerobiosis y se controlaron las colonias a las 24 y 48 horas. Se llevaron adelante 3 ensayos independientes por triplicado.

\section{Resistencia al pH}

Los efectos de un $\mathrm{pH}$ bajo sobre la viabilidad celular se analizaron por el método de Mayra-Makinen et al. (1983) con modificaciones. La bacteria se cultivó en $50 \mathrm{ml}$ de caldo MRS, en jarra de anaerobiosis sin agitación overnight. Posteriormente se separaron las células bacterianas desde el cultivo $(5 \mathrm{ml})$ por centrifugación a $3500 \mathrm{~g}$ por $20 \mathrm{~min}$. Se resuspendieron en $5 \mathrm{ml}$ de solución salina fisiológica a valores de $\mathrm{pH}$ de 1,9 y 3,0 y se incubaron por 30 min a $37^{\circ} \mathrm{C}$. Se determinó el número de células sobrevivientes por recuento en placa de MRS. Se utilizó como control una solución salina de $\mathrm{pH} 6,0$.

\section{Modelo gástrico in vitro}

Se realizó un modelo gástrico in vitro a los efectos de determinar la habilidad de las cepas aisladas de sobrevivir a la acción conjunta de condiciones ácidas y acción de proteasas que sufriría la bacteria luego de la ingestión (Crittenden et al., 2001).

Un cultivo bacteriano cultivado en las condiciones ya descriptas se centrifugó a 3500 g durante 20 min y se resuspendió en una solución de peptona bacteriológica ( $1 \mathrm{~g} / \mathrm{l})$ antes de la fase estacionaria de crecimiento. Luego se adicionaron igual número de bacterias al modelo gástrico y a un tubo control a una concentración final de $1 \times 10^{8} \mathrm{ufc} / \mathrm{ml}$ ajustada por medidas de absorbancia a $560 \mathrm{~nm}$. La solución en los tubos control consistió en $6 \mathrm{ml}$ de buffer fosfato $6 \mathrm{M}$ pH 6.5 y $1 \mathrm{~g} / \mathrm{l}$ de peptona bacteriológica. El modelo gástrico in vitro contenía $6 \mathrm{ml}$ de un jugo gástrico simulado con buffer $\mathrm{HCl} / \mathrm{KCl} 0.1 \mathrm{M} \mathrm{pH} 2.1$ conteniendo $500 \mathrm{U} / \mathrm{ml}$ de pepsina A y $1.0 \mathrm{~g} / \mathrm{l}$ de peptona bacteriológica. Se incubaron las células en el modelo y en el control por $60 \mathrm{~min}$ a $37{ }^{\circ} \mathrm{C}$ en condiciones aerobias sin agitación. Se tomaron muestras en tiempo cero y tiempo final y se determinó la concentración bacteriana por recuento en placa de MRS. Fueron conducidos tres ensayos por triplicado.

\section{Resultados y discusión}

\section{Aislamientos e identificación}

Se realizó una identificación primaria de la cepa seleccionada que resultó Gram positiva (Figura I), exhibió buen crecimiento aerobio y anaerobio, prueba catalasa negativa, bacterias no móviles y no esporuladas y disposición en bastones encadenados. Según la identificación realizada con el API $50 \mathrm{CH}$ se trata de una cepa de Lactobacillus acidophillus con un $97 \%$ de confianza.
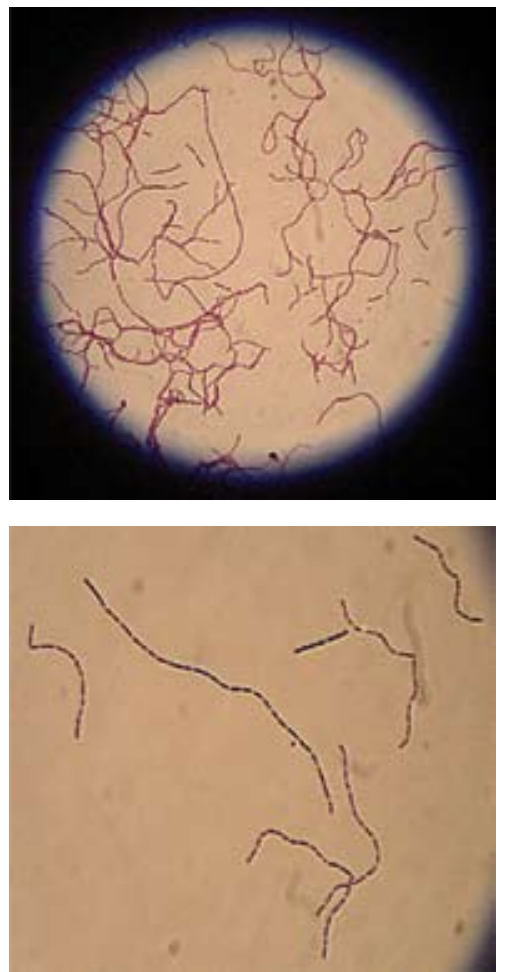

Figura I. Fotografías de tinciones Gram de la cepa de Lactobacillus seleccionada.

\section{Tolerancia a sales biliares}

Como puede verse en el gráfico I casi el $60 \%$ de la cepa puede crecer y desarrollarse en una concentración de sales biliares de 0,5\% del medio luego de $48 \mathrm{~h}$ de incubación. Cuando se aumenta la concentración al 0,9\% se produce una disminución en el crecimiento que oscila entre el 47 y el $50 \%$ con respecto al control.

\section{Resistencia a Sales Biliares}

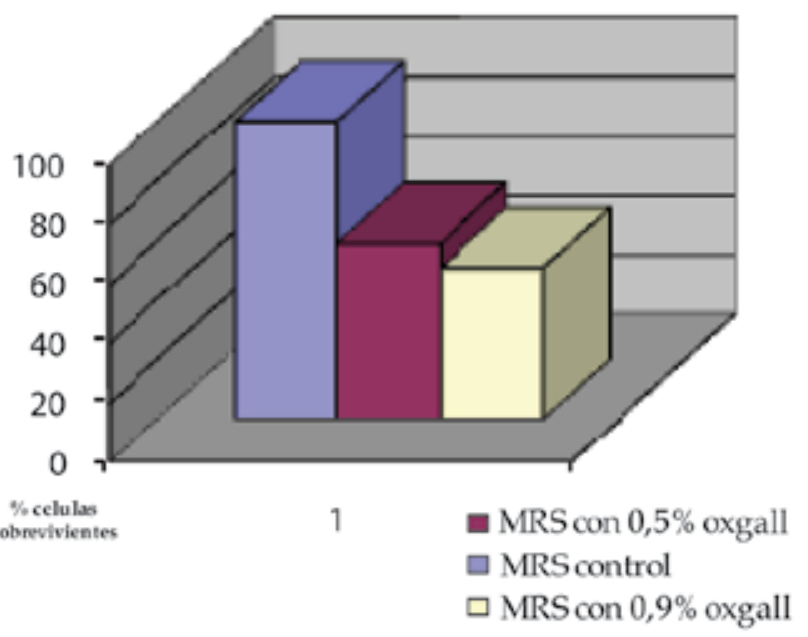

Gráfico I. Resistencia a sales biliares determinada por recuento en placa con $0,5 \%$ y $0,9 \%$ de sales biliares. 


\section{Resistencia al pH}

Al someter la bacteria a valores extremos de $\mathrm{pH}(3,09$ y 1,91$)$ en comparación con un valor control $(\mathrm{pH} 6,1)$, puede observarse una disminución de la concentración celular del 18 y $90 \%$ respectivamente luego de 30 min de exposición.

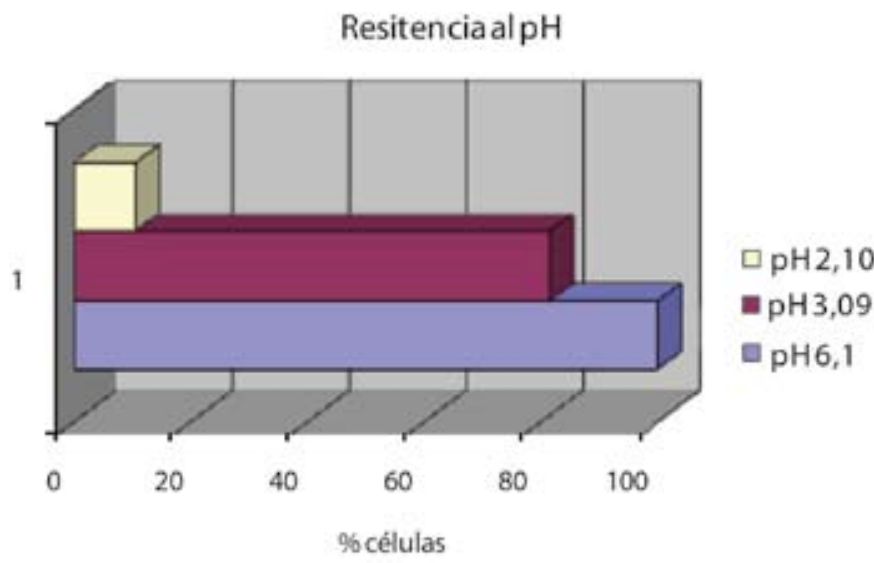

Gráfico II. Resistencia al pH de la cepa expresada como el \% de células sobrevivientes comparadas con un control con $\mathrm{pH}$ sin modificar.

\section{Modelo gástrico in vitro}

Como puede verse en el gráfico III, aproximadamente el $20 \%$ de la población bacteriana sobrevive a la acción combinada del $\mathrm{pH}$ y proteasas, similares condiciones a las que la bacteria tendría que soportar luego de su administración oral (60 min de exposición). También puede apreciarse que más de un $20 \%$ no sobrevive en el control por lo que la peptona bacteriológica no sería un medio óptimo para la supervivencia bacteria. De todos modos, podría inferirse que si se considera como $100 \%$ el número de bacterias que sobreviven en el control (78,6\% del recuento inicial), el 24,6\% de las bacterias sobrevivirían a la acción del medio gástrico.

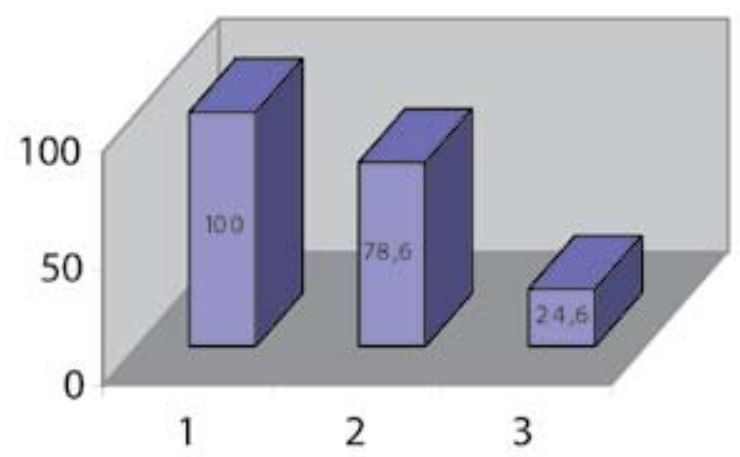

Gráfico III. Modelo Gástrico 1. Población bacteriana inicial en el modelo (100\%) 2.

Gráfico III. Modelo Gástrico 1. Población bacteriana inicial en el modelo (100\%) 2. Porcentaje de células sobrevivientes luego de 60 min de incubación $(\mathbf{7 8 , 6} \%)$ 3. Porcentaje de células sobrevivientes a un pH 2,1 con respecto al control a tiempo $60 \mathrm{~min}$

\section{Conclusiones}

$E^{n}$ base a los resultados obtenidos hasta el momento y a la idenificación realizada con el test API $50 \mathrm{CH}$ podemos afirmar que hemos aislado una cepa pura de Lactobacillus acidophilus 1 con un $97 \%$ de confianza.

Las cepas deben enfrentarse en su pasaje a través del tubo digestivo a condiciones ácidas en el estomago y a la exposición a la bilis en el intestino. Los resultados obtenidos en cuanto a la modificación de la viabilidad de la cepa expuesta a condiciones ácidas similares al pH estomacal y la exposición de la misma a sales biliares como modelo de la exposición a la bilis en el organismo, permiten afirmar que nuestra cepa presenta la habilidad de sobrevivir a éstas condiciones. Las mismas son requisito imprescindible para poder considerar a la bacteria como probiótica.

Los resultados del modelo gástrico realizado permiten afirmar que más del $24,6 \%$ de las células bacterianas sobrevivirían el pasaje a través del estómago, porcentaje notoriamente mayor al obtenido cuando se estudiaron sólo los efectos de un pH ácido.

\section{Referencias}

Borbonet, S. Historia de la quesería en Uruguay. Montevideo : Laboratorio Tecnológico del Uruguay. 2001.

Crittenden, R.G.; Morris, L.F.; Harvey, M.L.; Tran, L.T.; Mitchell, H.L. 2001. Selection of a Bifidobacterium strain to complement resistant starch in a synbiotic yoghurt. En: Journal of Appl. Microbiol. (90):268-278.

FAO; WHO. Evaluation and nutricional properties of powder milk and live lactic acid bacteria. Córdoba.: Food and Agriculture Organization of the United Nations and World Health Organization. 2001

Klaenhammer, T.R.; Kleeman, E.G. 1981. Growth characteristics, bile sensitivity, and freeze damage in colonial variants of lactobacillus acidophilus. En: Appl. Environ. Microbiol, (41): 1461-1467.

- Madrid, A. Manual de tecnología quesera. Madrid : AMV Ediciones. 1990.

- Mayra-Makinen, A.; Manninen, M.; Gyllenberg, H. 1983. Streptococcus suis adhesin protein and method for producing it. En: Journal of Appl. Bacteriology (55):241-245

- Reid, G. 1999. The Scientific Basis for probiotic strains of Lactobacillus. En: Appl. Environ. Microbiol. (65):3763-3766

- Tamine A. Y.; Robinson R. K. Yogur : ciencia y tecnología. Zaragoza : Acribia. 1991.

\section{Nota}

Este trabajo fue realizado en el marco del proyecto "Innovación y Desarrollo de Fermentos Lácteos. Obtención de Probióticos en Forma Comercial" seleccionado por el LATU en el llamado a Proyectos de Innovación y Desarrollo del 2005. 